\title{
Simultaneous and Sequential Anticommons
}

\author{
by \\ FRANCESCO PARISI, NORBERT SCHULZ, AND BEN DEPOORTER*
}

This paper defines a framework for anticommons analysis based on the fragmentation of property rights. In differentiating between sequential and simultaneous cases of property fragmentation, we describe and assess the equilibria obtained under each scenario. Our model reveals how the private incentives of excluders do not capture the external effects of their decisions. Moreover, our model suggests that the result of underutilization of joint property increases monotonically in both (a) the extent of fragmentation; and (b) the foregone synergies and complementarities between the property fragments. Within this context, we can therefore explore important implications for possible institutional responses to a range of issues raised by the concept of property fragmentation. (JEL: K10, K11, K19, D62, D70)

\section{Introduction}

Literature regarding common property has recently enjoyed significant discussion and debate regarding a new theory known as a "Tragedy of the Anticommons." Many scholars, alert to the myriad problems raised by the fragmentation of property rights, have closely examined what has become termed "anticommons" property regimes (Heller, 1998; Heller and Eisenberg, 1998; Buchanan and Yoon, 2000; Parisi, 2002; Depoorter and Parisi, 2001; Schulz, Parisi and Depoorter, 2003). That is to say, when multiple owners, each possessing a right to exclude others from a scarce resource, are prevented from maximizing his privilege of use, the resource may be wasted; this is a problem known as the Tragedy of the Anticommons. ${ }^{2}$

The economic literature has revealed the duality of commons and anticommons problems. Both problems have been shown to be the consequence of a lack of conformity between use and exclusion rights (Schultz, Parisi and Depoorter 2003). In situations where multiple individuals are endowed with the privilege to use a given resource, without a cost effective way to monitor and constrain each other's use, the resource is vulnerable to overuse, leading to a problem known as the tragedy of the commons. Symmetrically, when multiple owners hold effective rights to exclude others from a scarce resource, and no one has an effective privilege of use, the resource might be prone to underuse, leading to a problem known as the tragedy of the anticommons. 
An anticommons property regime occurs when multiple owners of some property hold effective rights of exclusion but insufficient rights to maximize the use of the property, ${ }^{3}$ which is an underuse tantamount to waste. Once a common resource is subject to multiple exclusion rights held by two or more individuals, each co-owner has incentives to prevent other users from using the resource at an efficient level. Despite the fact that the common resource would be used to its highest and best use by a single owner, the existence of coowners seeking to exert their individual exclusion rights will cause them to fall short of the net social benefits of the asset. The Tragedy of the Anticommons is the result of common resources remaining idle even when there could be some net social benefit. It occurs simply because the multiple holders of exclusion rights do not fully internalize the cost created by the enforcement of their right to exclude others.

Generally, there are two sources of externalities in an anticommons problem. First, there are static (or current) externalities, in that the exercise of a right of exclusion by one member reduces or eliminates the value of similar rights held by other individuals. One can think of this externality, in price theory terms, as the cross price effect of various exclusion rights. Second, withholding productive resources may create dynamic (or future) externalities because the underuse of productive inputs today bears consequences into the future, as standard growth theory suggests.

Elsewhere, we establish a dual model of property that illustrates that commons and anticommons problems result from opposing but similar departures from a unified conception of property (Schulz, Parisi and Depoorter, 2003). Consider the traditional structure of a property right held in fee simple as the normal case. In a fee simple regime, owners enjoy a bundle of rights which include, among other things, the right to maximize the use of property and the right to exclude others from it. What characterizes a typical fee simple situation is the fact that the owner exercises his rights of use and exclusion over the same domain. The right to use and the right to exclude are, in this sense, complementary attributes in a unified bundle of property rights.

Exploring the concepts of commons and anticommons regimes requires one to depart from this benchmark conception of unified property. In both commons and anticommons cases the rights of use and exclusion have non-conforming boundaries. They constitute symmetric departures from the unified conception of property. Simply, in commons situations, the right to use significantly exceeds the effective right (or power) to exclude others. Conversely, in anticommons situations, the co-owners' right of use is mitigated, and potentially eliminated, by an eclipsing right of exclusion held by competing co-owners. Thus, one can see in both commons and anticommons cases that rights of use and rights of exclusion have non-conforming boundaries that cause a net welfare loss from the forgone synergies between those complementary features of a coherent, unified property right. Welfare losses are produced by a discrepancy between the rights of use and 
the rights of exclusion held by the various owners.

The fact that commons and anticommons cases seem to mirror each other results from a misalignment of the private and social incentives of multiple owners in the use of a common resource. This misalignment is due to externalities not captured in the calculations of those who seek to maximize their use (commons situations) and those who seek to exclude all others from any use (anticommons situations).

In the following section, we provide a general formalization of the anticommons. In Section 3, we use our findings to explore possible institutional responses to fragmentation, as found in various legal systems.

\section{Modeling the Anticommons Tragedy}

Anticommons analyses are becoming more significant throughout both economic theory and law and economic scholarship. The essential model of the anticommons problem is a situation that results from a lack of conformity between use and exclusion rights. We elaborate a general model which we then utilize to distinguish between simultaneous and sequential cases. Certainly, reality may present situations that combine characteristics of the two categories, but initially, it is ideal to consider each hypothesis separately, to facilitate our understanding of the different equilibrium results.

In the simultaneous case, various right holders exercise exclusion rights at the same time, independently. This may involve two agents linked in a coincident relationship, such as multiple co-owners with cross-veto powers on other members' use of a common resource. We can think of multiple, independent owners pursuing a joint project which requires the unification of multiple, individually-owned parcels of land. It is important to note that in these situations, the agents hold and utilize rights on the same level of a value chain. $^{4}$

In the sequential case, the exclusion rights are exercised in consecutive stages, at different levels of the value chain. ${ }^{5}$ The various right holders exercise exclusion rights in succession. This may involve multiple parties in a hierarchy, each of whom can exercise exclusion or veto power over a given proposition. We can think of multiple-level fragmentation of land as a situation that would pose a sequential anticommons problem in the process of reunification. As an example, consider a subinfeudation of land fragmenting control in a pyramid-like structure. When unitary property is horizontally fragmented into limited real rights over land (e.g., a fee-simple owner grants building rights to a third party, who in turn, grants a partial use right to another), the conditions for a sequential anticommons problem are present. ${ }^{6}$ If reunification of land in fee simple is desired, a vertical chain of contracting would be necessary (e.g., in the example above, the grantor of the building rights would have to repurchase those rights from his grantee; in turn, the grantee of building rights would have to 
repurchase the partial use rights that he granted, and so on). ${ }^{7}$

Both simultaneous and sequential anticommons problems are the result of non-conformity between use and exclusion rights. The consequences of the general case presented in Section 2.1. are fully descriptive of simultaneous anticommons, under conditions of initial symmetry. No such symmetry can be expected in sequential anticommons cases, because of the unavoidable structural difference of the initial conditions (e.g., sequential moves of agents, upstream versus downstream firms, etc.). Section 2.2. concentrates on the results of such asymmetric cases.

\subsection{Independent Exclusion Rights: Understanding Simultaneous Anticommons}

In a simultaneous anticommons case, various rights holders exercise exclusion rights independently at the same level of a production or decision process. As an illustration, we can think of the choice of multiple land owners on whether to contribute their property for a joint venture development. Each parcel of land enters at the same level as an input of production for the joint development. If all parcels of land are necessary for the realization of the development, the multiple parcel owners would effective hold a cross-veto power for the realization of the joint project. As shown by Buchanan and Yoon (2000) and Schulz, Parisi and Depoorter (2003), the Tragedy of the Anticommons is the mirror-image case - in name and in fact - of the well-known Tragedy of the Commons. In terms of efficiency the problem of the anticommons is based on a positive externality, while the problem of the commons is based on a negative externality. ${ }^{8}$

In order to keep the model simple, we consider the case of two agents and we denote the activities of these agents using the common resource by $x_{i}$.

In anticommons cases $x_{i}$ denotes the extent to which agent $i$ grants agent $j$ permission to use the common property. In such cases, an activity $x_{1}$ of agent 1 exerts a positive impact on the productivity of agent 2 's activity $x_{2}$. Conversely, in commons cases, $x_{i}$ represents the extent to which agent $i$ uses the common resource. Due to the negative externality of each user on the residual productivity of the joint resource, an activity $x_{1}$ of agent 1 exerts a negative impact on the productivity of agent 2 's activity $x_{2}$. For the purpose of our illustration, the meaning of the parties activities in the anticommons and commons cases would necessarily differ. In the anticommons case, individual owners are faced with the prospect of a joint project, requiring each owner to contribute his own parcel for the joint venture. Here, $x_{i}$ denotes the extent to which agent $i$ contributes the private land for the common project. In the commons case, parties are faced with the opposite dilemma. There, $x_{i}$ would denote the extent to which agent $i$ uses the common land for a private purpose. 
For the general case, let us denote the value of the common resource to agent $i$ by $V_{i}\left(x_{i}, x_{j}\right)$. In a typical anticommons situation, the two agents hold exclusion rights that limit each other's ability to use the property. Neither agent has a right to use the resource without the consent of the other. In our example, this means that each party can withhold his parcel of land from the joint project and, by doing so, reduce the value of opportunities for the other prospective participants to the joint venture. In this context, agent $i$ grants agent $j$ the right to utilize the parcel of land for the joint development. Agent $j$ owns a complementary right to exclude agent $i$ from his parcel of land, equally necessary for the success of the joint development. The two agents may choose to grant each other some limited right of use of the resource for the joint project. The extent of the respective grants will be denoted as $x_{i}$ and $x_{j}$. Then $V_{i}\left(x_{i}, x_{j}\right)$ may denote the profit agent $i$ derives from this joint project. The positive externality that agent $j$ exerts on $i$ 's value can be modeled as

$$
\frac{\partial V_{i}}{\partial x_{j}}\left(x_{i}, x_{j}\right)>0
$$

Let's continue our analysis contemplating the case of exclusion rights exercised simultaneously and independently by various right holders. In such anticommons situations, multiple owners exercise veto power on equal terms.

To keep things simple, let us assume that both agents are in a perfectly symmetric situation. This will be modeled as $V_{i}\left(x_{i}, x_{j}\right)=V_{j}\left(x_{j}, x_{i}\right)$. As a result of their uncoordinated choices, each agent $i$ will choose the value of $x_{i}$ which maximizes $V_{i}\left(x_{i}, x_{j}\right)$. For the two player case, the resulting Nash equilibrium is characterized by the two first order conditions:

$$
\frac{\partial V_{1}}{\partial x_{1}}\left(x_{1}, x_{2}\right)=0 \quad \text { and } \quad \frac{\partial V_{2}}{\partial x_{2}}\left(x_{2}, x_{1}\right)=0
$$

It is natural to assume that $V_{i}$ is concave in $x_{i}$. Therefore such an equilibrium exits for mild assumptions on activities $x_{i}$. Given the initial symmetry assumption, we should expect a symmetric equilibrium $x_{1}=x^{c}=x_{2}$.

This characterization of the uncoordinated choices of the two agents can now be compared to the efficient choices of $x_{i}$, which we model as the choices that maximize $V_{1}+V_{2}$. These are characterized by the following first order conditions: 


$$
\frac{\partial V_{1}}{\partial x_{1}}\left(x_{1}, x_{2}\right)+\frac{\partial V_{2}}{\partial x_{1}}\left(x_{2}, x_{1}\right)=0 \text { and } \frac{\partial V_{2}}{\partial x_{2}}\left(x_{2}, x_{1}\right)+\frac{\partial V_{1}}{\partial x_{2}}\left(x_{1}, x_{2}\right)=0
$$

Given the symmetry assumption, a symmetric optimum is to be expected. Indeed it is again natural to assume that $V_{1}+V_{2}$ is concave and that (3) admits a symmetric solution. Hence, the efficient choices of both agents are equal: $x_{1}=x^{s}=x_{2}$.

It is now easy to see that $x^{s}>x^{c}$. The uncoordinated choices of the two agents lead to underutilization of the common resource. The intuition for this result was already mentioned above. In formal terms, recall that the two equations in (2) correspond to the best response functions of the two agents. The equilibrium is the intersection point of these two response functions. Now compare (2) and (3) and concentrate on the respective first equations. We now argue that the graph of the solution to the first equation in (3) must lie entirely above the best response function of agent 1 . For any value of $x_{2}$, denote $x_{1}\left(x_{2}\right)$, the value of the best response function of agent 1. Due to the positive externality (assumption (1)), inserting these values on the left hand side of equation (3) yields a positive value. Furthermore, due to the concavity assumption, the left hand side decreases in $x_{1}$. Hence, to satisfy this equation the value of $x_{1}$ satisfying (3) for the momentarily fixed value of $x_{2}$ must be greater than $x_{1}\left(x_{2}\right)$, which is to say that the graph implied by (3) is above the best response function of agent 1 . As symmetry implies that $x^{s}$ and $x^{c}$ are characterized by the respective intersection point of these two graphs with the 45 degree line, it follows immediately that $x^{s}>x^{c}$. This leads to the result that the uncoordinated exercise of exclusion rights leads to underutilization of a common resource.

The anticommons problem derives from externalities created by the agent's choices. In our illustration, one agent's choice to contribute his property for the proposed joint project benefits the owners of other property parcels. Conversely, the right to exclude the property from the common project creates a negative externality on the others. In the specific context, the owner's exclusion rights are exercised by means of withholding the private parcel of land from the reunification necessary to accomplish the joint project. In our model, exclusion rights can be formalized as follows: Let $y_{i}$ denote the extent of an exclusion right. If $x$ is the maximum possible extent of using a property, $y_{i}=x-x_{i}$ relates the extent of exercising an exclusion right, and where $x_{i}$ would represent the extent of the party's participation to the joint project. ${ }^{9}$

Our model of property reveals that the private incentives of users (commons case) and excluders (anticommons case) do not capture the external effects of their individual decisions. This leads to an excessive level of use or exclusion, with the symmetric results of overuse (commons) or underutilization (anticommons) of the joint property. In our illustrations, the dual implications of the model would suggest that there will be an excessive rate of exploitation of common resources for private purposes (commons) and a suboptimal rate of 
contribution of private resources for the joint venture (anticommons), with symmetric inefficiencies in the exploitation of those assets.

It should be noted that in many real world applications, the choices available to the parties are binary. That is to say, parties can choose to allow the joint project or to veto it, with no intermediate opportunities. In such cases, it may be more useful to think of the problem in terms of prices demanded by the parties to grant permission for the joint project. The above model of "exclusion" rights has indeed a parallel formulation where the two agents control the prices of their rights of use or exclusion, $p_{i}, p_{j}$, instead of their quantities, $x_{i}, x_{j}$. Such a dual version is analytically easier to represent if the two property rights are indivisible and strict complements. ${ }^{10}$ Let $p_{\mathrm{i}}$ denote the price which agent $i$ asks for giving up his right to exclude. Let $V_{i}\left(p_{i}, p_{j}\right)$ denote the value which agent $i$ derives from selling his right. As the two rights are, by assumption, complements, it is natural to assume

$$
\frac{\partial V_{i}}{\partial p_{j}}\left(p_{i}, p_{j}\right)<0 .
$$

Analytically this corresponds directly to the problem of the commons. In the commons problem, the external effects of the "use" decisions result in over-utilization, possibly even depletion of the common resource. In the present setting, the external effects of the "exclusion" decision generate higher than efficient prices, with a resulting underutilization of the common resource. In this form, the suggested price-driven model of the anticommons is the general version of the example contemplated by Buchanan and Yoon (2000). ${ }^{11}$

Our general treatment is helpful in at least two respects. First it allows, but does not require, strict complementarity. The two exclusionary rights may be partial (or less-than-perfect complements). The Buchanan and Yoon (2000) article assumes strict complementarity and thus represents a special case of our general model. Cases of partial exclusion rights are conceivable in real life property relations. One can think of several situations where the encumbrance of a third party exclusion right reduces, yet does not eliminate, the right of use (and the value) of the burdened property (such as a state-owned right of way). More generally, one can think of various hypotheses of less-than-perfect complementarity between the two rights.

The relevant variable along the anticommons continuum is the degree of substitutability, or complementarity, between the various components of our bundle of property rights. In the anticommons case, the exclusion rights are perfect complements with respect to the valued use of the property (e.g., the consent of all exclusion right holders is necessary for any use of the joint property). 


\subsection{Multiple Rights Holders and Sequential Anticommons}

In a sequential anticommons situation, exclusion right holders are in a serial relationship with one another, and choices are made consecutively by the various right holders. Also in this case, the likely result is that suboptimal equilibria may occur because of the presence of external effects of quantity or price restrictions. Similar to the other anticommons situations, we assume every agent benefits from another agent's activity, leading to a positive externality. Symmetrically, every agent occasions a negative externality to other agents when reducing his own activity or increasing a price. In the context of our illustration, each party can withhold his parcel of land from the joint project and, by doing so, create a negative externality due to the reduced value of opportunities for the other prospective participants to the joint venture.

In the sequential anticommons, the position of the two parties is asymmetric with respect to one another. We can think of the sequential anticommons as a generalized version of the traditional hold-up problem (e.g., Hart, 1995). Consider two independent firms (or individuals), one located downstream and the other upstream. The upstream firm 2 invests $x_{2}$ with costs $C_{2}\left(x_{2}\right)$. The downstream firm 1 bears $\operatorname{costs}$ of $C_{1}$ ( $\left.x_{1}\right)$ relating to her investment. Both investments have a positive impact on the revenue of firm $1, R\left(x_{1}, x_{2}\right)$. If both exclusive rights to determine the investment levels were united in one hand, such an agent would choose the levels maximizing

$$
W\left(x_{1}, x_{2}\right)=R\left(x_{1}, x_{2}\right)-C_{1}\left(x_{1}\right)-C_{2}\left(x_{2}\right) .
$$

As long as these exclusive rights remain in the hands of the two agents respectively, the agents must agree on some rules to divide the resulting profits. Let $U\left(x_{1}, x_{2}\right)$ be the amount which firm 1 agrees to pay to firm 2. In the hold-up literature, $U$ is modeled as the Nash-bargaining solution of the underlying bargaining situation. This implies the following value to the two agents:

$$
\begin{aligned}
& V_{1}\left(x_{1}, x_{2}\right)=R\left(x_{1}, x_{2}\right)-C_{1}\left(x_{1}\right)-U\left(x_{1}, x_{2}\right) \\
& V_{2}\left(x_{2}, x_{1}\right)=U\left(x_{1}, x_{2}\right)-C_{2}\left(x_{2}\right) .
\end{aligned}
$$

Using the interpretation of $U$ as the outcome of the Nash-bargaining solution, we can impose the following assumptions. $U$ has positive first partial derivatives. Hence, the investments lead to a higher compensation for firm 2. Moreover, the impact of the investments in $x_{2}$ on the revenue of firm 1 is not fully 
reflected in $U$. Analytically, this means that the first partial derivative of $U$ with respect to $x_{2}$ is smaller than this partial derivative of $R$. Finally, we assume that $V_{i}$ is concave in $x_{i}$, and the first and second cross partial derivatives of $V_{i}$ are positive. All these assumptions occur in the typical hold-up model.

Now consider the uncoordinated choices of the two agents, each choosing the level of investment maximizing his own value. The first order conditions for this problem read:

$$
\begin{aligned}
& \frac{\partial V_{1}}{\partial x_{1}}=\frac{\partial R}{\partial x_{1}}\left(x_{1}, x_{2}\right)-\frac{\partial C_{1}}{\partial x_{1}}\left(x_{1}\right)-\frac{\partial U}{\partial x_{1}}\left(x_{1}, x_{2}\right)=0 \\
& \frac{\partial V_{2}}{\partial x_{2}}=\frac{\partial U}{\partial x_{2}}\left(x_{1}, x_{2}\right)-\frac{\partial C_{2}}{\partial x_{2}}\left(x_{2}\right)=0 .
\end{aligned}
$$

Compare these conditions to the ones that would be relevant if the investment decisions were chosen by just one agent:

$$
\frac{\partial R}{\partial x_{1}}\left(x_{1}, x_{2}\right)-\frac{\partial C_{1}}{\partial x_{1}}\left(x_{1}\right)=\frac{\partial R}{\partial x_{2}}\left(x_{1}, x_{2}\right)-\frac{\partial C_{2}}{\partial x_{2}}\left(x_{2}\right)=0
$$

Using the same arguments expressed in the previous section, we show that the best response function of firm 1 lies below the graph of the solution of the first equation in (10). The same holds true for the best response function of firm 2 with respect to the second equation in (10). Furthermore, both response functions and the graphs of the solution of equations (10) are upward sloping because of their positive second cross partial derivatives. This implies that the intersection point of the best response functions must lie strictly below the point characterized by (10). Hence, the resource or right that is controlled by the respective exclusion rights of the two firms is underutilized, compared to the unified ownership alternative.

The sequential anticommons problem thus reveals the cost of sequential fragmentation of use and exclusion rights, as manifested in the deadweight loss resulting from the uncoordinated action of the two sequential right holders. The result generally parallels the case of unexploited investment opportunities of two firms faced with a hold-up problem in an investment decision.

Again, we have the result that the lack of consonance between use and exclusion rights over a resource leads to a suboptimal use of the resource. In exercising non-conforming exclusion rights, firms and individuals 
do not take into account the external effects of their decisions. In the specific case of sequential anticommons, the misalignment is due to the positive externalities that are not captured in the calculus of interests of the upstream excluders, leading to the underutilization of the resource.

Analogous results are obtained when considering the equilibrium outcomes of price-driven restrictions. ${ }^{12}$ In all the categories contemplated above (i.e., in both activity and price versions of the simultaneous and sequential anticommons), the problem of underutilization is exacerbated if the right is fragmented into more than two exclusion rights, with more than two agents deciding independently on their activity or price (Schulz, 2000). ${ }^{13}$

These results are the consequence of the fact that the concerned parties do not have an opportunity to internalize the full benefit of their activity. Because none of the investing parties obtains the full increment of the resulting revenue from an increase in investment, due to the bargaining process, each will invest less than the efficient amount. In the context of our working example, this leads to a suboptimal rate of reunification of property for the purpose of the development project. Each party withholds his partial property right and, by doing so, creates a negative externality which reduces the value of opportunities for the other prospective participants to the joint venture.

\section{Discussion of the Anticommons Analysis}

We demonstrated above that the very nature of the fragmentation of property rights, not merely the extent of it, results in anticommons, with a direct impact on the deadweight loss. ${ }^{14}$ The model predicts that Anticommons losses increase monotonically in both (a) the extent of fragmentation; and (b) the foregone synergies and complementarities between the property fragments.

An important implication of such monotonousness is the fact that it is easier to divide a packet of property rights than to reassemble it. Put differently, at the margin, a single owner faces no strategic costs when deciding whether to fragment. But, following fragmentation, reunification requires the involvement of at least two parties, with accordant and influencing transaction costs; and, more costs for greater numbers of parties. This creates one-directional stickiness in the process of reallocating property at different levels of fragmentation. 


\subsection{Asymmetric Transaction Costs}

In a world of zero transaction costs, an efficient allocation of resources occurs regardless of the initial allocation of legal entitlement and choice of remedies to protect them. ${ }^{15}$ In our context, the Coase theorem suggests that if all rights are freely transferable and transaction costs are zero, an inefficient initial partitioning of property rights will not impede an efficient final use of the resources. In the event of inefficient fragmentation of property, voluntary agreements will reaggregate property into the most efficient clusters, maximizing the total value of the resources.

Once the ideal conditions of the positive Coase theorem are relaxed however, over-fragmentation poses the interesting situation of asymmetric transaction costs. The presence of such asymmetry is due to the fact that the reunification of fragmented rights involves transaction and strategic costs of a greater magnitude than those incurred for the original fragmentation of the right. Simply, a single owner faces absolutely no strategic costs when deciding how to partition his property. Conversely, as shown in Section 2, each of multiple non-conforming co-owners are faced with a strategic problem, given the interdependence of their decisions. The equilibrium pricing (or quantity supply) of anticommons owners will impede the optimal reunification of non-conforming fragments into a unified bundle.

In the context of the anticommons, the argument that it is often harder to reunify dispersed rights rather than to fragmentize coherent bundles has been expressed by Heller (1998). While intuitively correct, this notion warrants further explanation.

In selecting the optimal level of fragmentation, a rational owner estimates the expected value of the alternative partitioning of his property and would rationally select the arrangement that yields the highest net present value. The owner's optimal choice would rest on the estimation of (a) the respective probability that each alternative partitioning may coincide with the desired final allocation, and (b) the respective ex post reallocation costs (if the chosen level of fragmentation proves to be ex post sub-optimal). This optimization process leads to the choice of an initial allocation that maximizes the present value of the property at the net of possible reallocation costs and resulting inefficiencies. In this respect, owners act efficiently, utilizing all available information and with full consideration of the asymmetric transaction costs induced by property fragmentation.

In spite of the perfect alignment of private and social incentives, anticommons problems remain. Owners certainly aim to maximize the value of their property, but - given a level of uncertainty on the optimal final use - they do so with some normally distributed margin of error. Because of the one-directional stickiness in the fragmentation process (i.e., sub-optimal fragmentation can be easily corrected ex post, while excessive 
fragmentation is likely to be irreversible) the normal distribution of errors has cumulative, rather than offsetting, effects on society. ${ }^{16}$

The interesting point here is that, while anticommons fragmentation may be occasionally ex ante efficient (given the specific goals pursued by property owners), it may result in strikingly inefficient ex post allocations.

\subsection{Policy Implications of Anticommons Analysis}

In the realm of non-conforming property arrangements, positive transaction costs often generate a onedirectional stickiness in the transfer of legal entitlements. Clearly, externalities and holdouts are two significant impediments to transfers. The challenges of policy makers can be assessed by applying the formal analysis in Section 2 above to illustrate the presence of anticommons deadweight losses. In revealing the economic mechanism operating within property fragmentation, we may achieve a better understanding of the concrete legal rules found in many areas of law.

In this context, our findings yield a normative proposition, a testable hypothesis and an explanatory proposition, along the following three points.

1. The normative proposition contains a cautionary rejoinder in the current trend of vesting individual property right protection in an increasingly broader scope of resources. This trend is particularly current in the domain of intellectual property law. Several areas of intellectual property are gradually shifting away from a commons regime toward a private property regime. Under the older commons regime, much of the knowledge was freely available in the public domain. Given the public good nature of those discoveries and information, research was publicly funded. Today, much of that information is subjected to increased protection of intellectual property laws, which has served to gradually shift the balance toward the privatization of research. Research is frequently conducted on a competitive basis by research institutions and private firms. Whenever possible, the results of such research are generally patented, licensed or traded in the marketplace. This allows research firms and institutions to capture some of the value of their discoveries, with increased incentives for valuable research.

The transition from commons to privatization, while beneficial in terms of the creation of private incentives for research, generates a gradual proliferation of exclusion rights with resulting anticommons problems. ${ }^{17}$ As shown in Section 2 of this paper, anticommons problems are likely to be pervasive in the production of goods requiring highly complementary inputs supplied by independent parties. For example, the use of production technology protected by multiple third party patents occasions a fragmentation that can be 
analogized to the cases of non-conforming property discussed above. In this context, Heller and Eisenberg (1998) apply the anticommons concept to patent technology. They argue that granting too many patent rights in biomedical research may delay the discovery and production of life-saving products. Product developers are often faced with a difficult decision. Before they can develop new products and bring them to the market, they frequently need to solicit licenses from various patent holders. In the presence of positive externalities between upstream patent holders and downstream product developers, a situation parallel to the sequential anticommons setting described in Section 2.2 above, may emerge. The failure of parties to take into account these externalities may generate anticommons deadweight losses. In the context of intellectual property, privatization of research must, in this respect, be attentive to the need to promote research in the upstream market without delaying the discovery and implementation of downstream products.

More generally, "propertization" may be a good antidote for offsetting commons deadweight losses but, if carried out beyond measure, may lead to even greater losses from anticommons problems.

2. The positive hypothesis suggests that courts and legislators, consciously or unconsciously, already account for the asymmetric effects of property fragmentation when considering the optimal choice of rules and the optimal structure of remedies. Legal systems take into account the anticommons problems by implementing rules designed to minimize social losses of property fragmentation. One hypothesis is that legal systems would grant less extensive property-type protection in favor of non-conforming property arrangements. Several rules and doctrines in the field of real property can be evaluated in light of this hypothesis. Consider, for example, the mandatory rules in private land use law regulating the creation and enforcement of atypical easements and real covenants. While the Anglo-American law of promises with respect to land is frequently criticized as nothing more than a historically evolved legal cobweb, close examination reveals that behind its technicalities is a coherent economic logic. The attachment of promises to land creates user rights in a property resource, and as such, may be regarded as a partitioning of property rights. By treating land-related promises as enforceable contracts that bind the contracting parties rather than real rights that run with the land in perpetuity, doctrines such as touch and concern in common law, prediality ${ }^{18}$ and the numerus clausus ${ }^{19}$ principles in civil law, have served as instruments to limit the cases of dysfunctional fragmentation. ${ }^{20}$

The parties retain an unfettered freedom to contract, unrestrained in the domain of contractual and personal obligations. The creation of atypical property rights is, however, governed by categories and rules of contract law, with liability-type protection under most circumstances. ${ }^{21}$ The dichotomous treatment of typical and atypical property rights can be explained as an attempt to minimize the transaction and strategic costs resulting from less optimal property arrangements. 
3. Furthermore, our formal analysis of the anticommons tragedy, as presented above in Section 2, may provide an alternative explanation for the long-lived heritage of default reunification mechanisms, commonplace in virtually all systems of Western legal tradition. Time limits, statutes of limitation, liberative prescription, rules of extinction for non-use, etc., can all be regarded as legal devices to facilitate the (otherwise costly and difficult) reunification of non-conforming fragments of a property right. These legal solutions can be analogized to a gravitational force, reunifying rights that, given their strict complementarity, would naturally be held by a single owner. This tendency towards reunification works to rebundle property rights in order to regenerate the natural conformity between use and exclusion rights (and, more generally, between any two complementary fragments of property). Along similar lines, a survey of American property law by Michael Heller (1999) reveals what he terms a 'boundary principle' which limits the right to subdivide private property into wasteful fragments. Property law responds to excessive fragmentation with the use of a variety of rules and doctrines such as the rule against perpetuity, zoning and subdivision restrictions, property taxes and registration fees, etc. (see, Heller (1999, 1173-1174), citing zoning and subdivision restrictions such as minimum lot sizes, floor areas and setbacks that prevent people from spatially fragmenting resources too much). Heller suggests that, by making the creation and maintenance of fragments more costly, for instance through annual disclosure expenses, excessive fragmentation into low-value fragments will be deterred and existing fragments will be abandoned so that the state can afterwards rebundle them.

Interestingly, most of these reunification mechanisms do not apply with respect to typical property rights. Typical property rights already provide conforming boundaries of use and exclusion rights. This eliminates any reason to favor reunification over persisting fragmentation. Conversely, atypical property arrangements may justify the activation of reunification mechanisms to overcome entropy and persisting fragmentation (Parisi, 2002).

\section{Conclusion}

In this paper, we developed a model of anticommons fragmentation in property. In both sequential and simultaneous property fragmentation, underutilization of a scarce resource results from the fact that the private incentives of excluders do not capture the external effects of their individual decisions. Our simple model suggests that the results of underutilization of joint property increase monotonically in both (a) the extent of fragmentation; and (b) the foregone synergies and complementarities between the property fragments. This monotonicity implies that it is easier to fragment than to reconvene fragmented property. In the realm of non- 
conforming property arrangements, this generates one-directional stickiness in the transfer of legal entitlements.

The recognition of such one-directional transaction and strategic costs generates a promising research agenda for the study of laws and institutions designed to cope with such asymmetries. Along the lines of well known efficiency hypotheses of the common law, a positive hypothesis can be formulated according to which courts and legislators, consciously or unconsciously, account for the asymmetric effects of property fragmentation in designing default rules and remedies. This tendency may be reflected in the legal system's reluctance to grant extensive property-type protection in favor of non-conforming property arrangements and in the creation of default reunification mechanisms for atypical property right arrangements. As a general normative corollary we can anticipate a note of caution in the current trend of diffuse and fragmented "propertization" and a revival of the notions of unified and absolute property. It is a point of future research to expose various institutional responses to potential problems of excessive property fragmentation.

\section{References}

Alchian, A. (1965). “Some Economics of Property Rights." Il Politico. 30, 816-829.

Alchian, Armand A. (1977), 'Some Economics of Property Rights', in Alchian, Armand A., Economic Forces at Work, Indianapolis, Liberty Press.

Buchanan, J. and Y. Yoon (2000). "Symmetric Tragedies: Commons and Anticommons Property." Journal of Law and Economics. 43, 1-13.

Coase, R. H. (1960). “The Problem of Social Cost.” Journal of Law and Economics. 3, 1-44.

Depoorter, B. and F. Parisi (2001). "Fair Use and Copyright Protection: A Price Theory Explanation." GMU Law \& Economics Working Paper Series \# 01-03.

Eggertsson, T. (1990). "The Role of Transaction Costs and Property Rights in Economic Analysis." European Economic Review. 34, 450-457.

Hardin, G. (1968). "The Tragedy of the Commons." Science. 162, 1243-1248.

Heller, M.A. (1998). "The Tragedy of the Anticommons: Property in the Transition from Marx to Markets." Harvard Law Review. 111, 621-687.

Heller, M.A. (1999). “The Boundaries of Private Property.” Yale L.J. 108, 1163-1223.

Heller, M. and R. Eisenberg, (1998). "Can Patents Deter Innovation? The Anticommons in Biomedical Research', 280 Science, excerpted as 'Upstream Patents, Downstream Bottlenecks' in Law Quadrangle Notes. 4.13, 93-97.

Libecap, Gary D. and S. Wiggins (1984). "Contractual Respones to the Common PoolPt] American Economic Review. $74,84$. 
Merrill, T. and H. Smith (2000). "Optimal Standardization in the Law of Property: The Numerus Clausus Principle," Yale L.J. 110, 1-70 .

Miceli, T. J. (1996). Economics of the Law: Torts, Contracts, Property, Litigation, Oxford: Oxford University Press.

Michelman, Frank I. (1968). "Property, Utility and Fairness: Comments on the Ethical Foundations of 'Just Compensation' Law," Harvard Law Review. 80, 1165-1258.

Michelman, Frank I. (1982), 'Ethics, Economics, and the Law of Property', in Pennock, J. Roland and Chapman, John W. (eds.), Nomos XXIV: Ethics, Economics and the Law, New York, New York University Press, 3-40.

Parisi, F. (2001). "The Asymmetric Coase Theorem: Dual Remedies for a Unified Property," GMU Law \& Economics Working Paper Series \#01-13.

Parisi, F. (2002). “Entropy in Property.” American Journal of Comparative Law. 50, 701-738.

Rose, Carol M. (1986). "The Comedy of the Commons: Custom, Commerce, and Inherently Public Property.” University of Chicago Law Review, 53, 711-780.

Rose, Carol M. (1999). "What Government Can Do for Property."; In Mercuro \& Samuels (eds.) Fundamental Interrelationships between Government and Property. New York: Elsevier Science Press.

Schulz, N. (2000). "Thoughts on the Nature of Vetoes When Bargaining on Public Projects." Würzburg Economic Papers, 00-17.

Schulz, N., F. Parisi, and B. Depoorter (2003). "Fragmentation in Property: Vertical and Horizontal Anticommons." Journal of Institutional and Theoretical Economics (forthcoming).

Spengler (1950). "Sequential Integration and Anti-Trust Policy." Journal of Political Economy. 58, 347-352.

Tirole, J. (1993). The Theory of Industrial Organization. Cambridge, MA: MIT Press. ${ }^{22}$ 


\footnotetext{
* The authors would like to thank Clay Gillette, Richard Merrill, Andrew Sellgren and Paul Stephan, III for extremely helpful conversations, comments and advice
}

${ }^{2}$ The concept of the anticommons, first introduced by Michelmann (1982) and then made popular by Heller (1998 and 1999), refers to the reverse case of Hardin's (1968) well known Tragedy of the Commons.

${ }^{3}$ This definition of the anticommons employed by Heller (1998) provides a powerful tool for property theory. Heller (1998) recently revitalized the concept in an article on the transition to market institutions in contemporary Russia. He discusses the intriguing prevalence of empty storefronts in Moscow. Storefronts in Moscow are subject to underuse because there are too many owners (local, regional and federal government agencies, mafia, etc.) holding the right to exclude. Frank Michelman (1982) coined the term "anticommons" in an article on ethics, economics and the law of property. Michelman defined the anticommons as a type of property in which everyone always has rights respecting the objects in the regime, and no one, consequently, is ever privileged to use any of them except as particularly authorized by others, a situation which had almost no counterpart in real-world property relations. The hypothetical example provided is that of a wilderness preserve that 'any person' has standing to enforce.

${ }^{4}$ In our example, each owner of a parcel of land contributes an "input" for the joint project at the same level of the production process.

${ }^{5}$ This is meant to refer to a situation where one of the agents wants to pursue a project and needs to obtain the right of the other agent to do so. A classical textbook example of the double marginalization problem was first formalized by Spengler (1950), where the retailer needs the right to use an intermediate input of some producer. See also, Tirole (1993: 174).

${ }^{6}$ On property rights and transaction costs, see Miceli (1996). One can think of various examples of administrative procedures (e.g. filings for building permits, etc.) with multiple administrative bodies (e.g., zoning, environmental, etc.) 
exercising control over a given proposal.

${ }^{7}$ Real life applications of the sequential anticommons problem include bureaucracy-like situations, where multiple permits need to be acquired in order to exercise a given activity, or a production process where a given producer purchases an essential input from a monopolistic seller.

${ }^{8}$ In an ideal world of costless contracting, these externalities could be corrected by Coasian bargaining between the interested parties. Just as any monopoly or strategic hold-up would disappear in a zero transaction cost world, the anticommons problem would likewise be corrected by free contracting. When evaluating the effects of Coasian bargaining on the parties' incentives, however, we should realize that anticommons problems are an impediment to parties' bargaining and the externalities in question are the result of the parties' bargaining, rather than the object of their contracting. The ability of individuals to contract with third parties for the transfer of their parcel of property does not guarantee an equal ability for the various sellers to coordinate with one another in order to overcome the anticommons problem and internalize all relevant externalities.

${ }^{9}$ If $W_{i}\left(y_{i}, y_{j}\right)=V_{i}\left(x_{i}, x_{j}\right), W_{i}$ would inherit the concavity property from $V_{i}$ and would have first partial derivatives which have the inverse signs. This transformation of "use" rights into "exclusion" rights would therefore leave the qualitative nature of the general result intact.

${ }^{10}$ Exclusivity of property rights are often seen as a prerequisite of selling the property right. With the transfer of the property the right to exclude is transferred as well. In this view, a price of some property can also be seen as a price for the right to exclude others from using the property. This enables another variation of modeling the anticommons problem which is again a dual form of the first version.

${ }^{11}$ For illustrative purposes, it might be helpful to mention the example used by Buchanan and Yoon (2000). The authors consider the case of a common resource - a parking lot - jointly owned by two individuals. The two joint owners have autonomous exclusion rights. This implies that a third party who wishes to utilize the parking lot needs to obtain the consent of both co-owners. In their example, users have to purchase two tickets (one from each agent) at a price of $p_{i}$. The 
value of a user is $a-Q$, where $Q$ denotes the number of users. Note that the efficient number of users is therefore obtained by maximizing $Q(a-Q)$ which gives the value $Q^{s}=a / 2$. Note also that one agent owning the parking lot would choose the price $p^{m}=a / 2$ (each user pays the price $p=a-Q$, hence profits are $p(a-p)$ and the maximizing price is $a / 2$ ). Therefore this monopolist just chooses the efficient price. If the two agents charge prices without coordination among themselves, $p_{1}$ and $p_{2}$ respectively, the number of users has to satisfy $p_{1}+p_{2}=a-Q$. Hence $p_{1}$ and $p_{2}$ result in a demand for parking $Q=a-p_{1}-p_{2}$. This in turn leads to profits for agent 1: $p_{1}\left(a-p_{1}-p_{2}\right)$. Let each agent charge the price which maximizes his profit. The corresponding first order condition for agent 1 is: $a-2 p_{1}-p_{2}=0$. For agent 2 an analogous equation derives. This leads to equilibrium values of $p_{1}=p_{2}=a / 3$ or $p_{1}+p_{2}=2 a / 3$. Hence uncoordinated choices result in a higher price and therefore underutilization of the parking lot.

${ }^{12}$ In this sequential anticommons setting, the two agents' independent choice of prices can be analogized to a double marginalization problem. The classic result of double marginalization is suboptimal supply. Likewise, the sequential fragmentation of decision rights gives rise to underuse of resources in an anticommons setting. The general formulation of the sequential anticommons problem in price terms could proceed along the lines of the hold-up problem illustrated above. The choice of model for the illustration of anticommons problems obviously hinges in essential ways on the type of application under consideration. Nevertheless, the general conclusions remain quite robust for both: (a) simultaneous and sequential cases, and (b) price-driven and activity-driven forms of competition between the two right holders.

${ }^{13}$ Buchanan and Yoon (2000) show an increase in the number of agents with exclusionary rights enhances the problem of underutilization in their price-driven anticommons example. In more general form, Schulz (2000) shows that similar results are obtained in a quantity-driven anticommons setting. The results are consistent with the exacerbation of commons problem with an increase in the number of users. E.g., in the symmetrical commons case, the Libecap and Wiggins (1984) study on common pool oil resources documented the positive correlation between the number of involved parties and the preemptive exploitation of the common pool resource.

${ }^{14}$ In the existing literature, the expression "partitioning of property rights" refers conjunctively to spatial and functional 
forms of fragmentation. See, e.g., Alchian (1965 and 1977) describing situations when several people each possess some portion of the rights to use the land. He also provides examples of private land-use arrangements such as servitudes (e.g. the right to grow wheat on it, to dump ashes over it, etc.).

${ }^{15}$ Coase (1960). See also on attenuation and partitioning of property rights, Eggertsson (1990b, 38-39).

${ }^{16}$ Parisi (2001) notes that this optimization process requires the assessment of the likelihood of different situations arising in the future, and the evaluation of the impact of asymmetric transaction costs, given the uncertainty over the optimal final allocations. In our case, in order to solve the allocation problem under uncertainty, owners would consider: (a) the relative cost of reallocating from the initial allocation $i$ to the efficient allocation $j$, which the author denotes $C_{i j}$; and (b) the probability $P(i)$ that allocation $i$ is the most efficient final allocation, among the $n$ possible alternative allocations. The presence of asymmetric transaction costs renders the present optimization problem different from the usual optimal allocation problem of the normative Coase theorem. In the usual case with symmetric transaction costs, $C_{i j}=C_{j i}$, the optimization problem is simplified and reduces to an optimal choice driven by the respective probability of alternative efficient final allocations. The optimal initial allocation coincides with the most likely efficient final allocation (i.e., $i^{*}=$ $\operatorname{Max}\{P(i)\})$. In the presence of asymmetric transaction costs, $C_{i j} \bullet C_{j i}$, the optimization problem should, instead, account for the asymmetry induced by the one-directional stickiness in the exchange process. The optimal initial allocation is derived considering the costs and benefits of alternative allocations, in light of such asymmetry.

${ }^{17}$ In response to the standard conclusions derived from the Tragedy of the Commons phenomenon, Carol Rose (1986) has described how in certain circumstances the answer to depletion or overutilization of scarce resources is not found in granting private property rights. Rose illustrates this notion with striking examples of 'public property' where common law and statutory strategies have long provided the optimal resource management strategy.

${ }^{18}$ The requirement of prediality (art. 637 C.C. in Belgium and France, art. 646 Louisiana code) holds that only land promises which are of "real" nature may run with the land. Promises of personal nature are personal rights, not real rights, and as such, they do not pertain the characteristics of a real right. 
${ }^{19}$ The numerus clausus doctrine holds that there is a limited number of real property rights that the legal system recognizes and grants property-type remedial protection.

${ }^{20}$ Parisi (2002) evaluates the comparative and historical analysis of property rules concerning the creation and enforcement of atypical easements and real covenants in light of the positive hypothesis of transaction and strategic cost minimization. Rose (1999) and Merrill and Smith (2000) have used information-cost economics to explain the various legal efforts to avoid undue fragmentation. Their contributions concentrate on information costs and distinguish property from contract along the dimension of property law's preoccupation with avoiding fragmentation. Most specifically, Merrill and Smith (2000) provide an information-cost rationale to explain the numerus clausus doctrine as an attempt to constrain the proliferation of types of property rights leading to an increase in third-party information costs. For this reason, property law enforces as property only those interests that conform to a limited number of standard forms.

${ }^{21}$ This apparent anomaly in the coordination of property and contract rules has been overlooked in the literature. Recent research suggests that Anglo-American courts intuitively responded to the dangers of unrestricted fragmentation by obstructing the running of personal promises attached to land, in favor of objective arrangements intrinsic to the land in question. See Merrill and Smith (2000) and Parisi (2002). 